\title{
Factors associated with overweight and obesity in students of 5-14 age group in Mersin
}

\author{
(1) Serdar Deniz², (1) Hülya Şirin², (1) Mehmet Kıvrak³, (1) Züleyha Kaplan4, (1) Gamze Ketrez², (1) Sarp Üner \\ 1 Malatya Provincial Health Directorate, Malatya, Turkey \\ 2University of Health Sciences Turkey, Gülhane Faculty of Medicine, Department of Public Health, Ankara, Turkey \\ 3Inonu University Faculty of Medicine, Department of Biostatistics, Malatya, Turkey \\ 4Mersin Provincial Health Directorate, Mersin, Turkey \\ ${ }^{5}$ Hacettepe University Faculty of Medicine, Institute of Public Health, Ankara, Turkey
}

Date submitted:

11.02.2020

Date accepted:

05.05.2020

Online publication date:

15.12.2020

\section{Corresponding Author:}

Serdar Deniz MD, Malatya Provincial

Health Directorate, Malatya, Turkey

dr.serdardeniz@gmail.com

\section{ORCID:}

orcid.org/0000-0002-6941-4813

Presented in: It was presented as an abstract at the 20th National and $3^{\text {rd }}$ International Biostatistics Congress on October 26-29, 2018.

Keywords: Student, overweight, obesity

\begin{abstract}
Aims: Obesity is a health problem caused by excessive fat deposition in the body, which spreads rapidly, threatening the age group of children as well as adults. When it occurs in childhood, it probably continues in adulthood. This study aims to determine the factors related to overweight and obesity in primary and secondary school children in Mersin.

Methods: This cross-sectional study was carried out with the children aged between five and 14 years in primary and secondary schools in Mersin, following the school health activities done by Mersin Public Health Directorate. Minimum sample size was calculated as 1.735 and questionnaires were sent to 2.000 people considering the variables of the class and school location. The independent variables of the study were sociodemographic characteristics, feeding habits, time allocated for physical and other activities, children's body mass index (BMI) categories according to the parents' declarations and parents' BMI categories according to their declarations. And, the dependent variable was the children's BMI values calculated by our measurements. The data of 1.980 students were analyzed.
\end{abstract}

Results: The mean age of the study group was $9.28 \pm 2.53$ (minimum-maximum: 5-14) years, and $50.9 \%$ of them were male. It was found that $14.6 \%$ of the group were obese and $21.5 \%$ were overweight. While $38.3 \%$ of boys were in the overweight or obese category, this rate was $33.8 \%$ for girls $(p>0.05)$. The prevalence of overweight or obesity was significantly higher in secondary school students than in primary school students $(p<0.05)$.

Conclusions: The factors affecting childhood obesity identified in the studies conducted in Turkey have also become apparent in the current research we did on the school children aged 5-14 years in Mersin.

\section{Introduction}

Obesity, which is an increasing public health problem, has become an important health threat in children as well as adults. It occurs as a result of an excessive storage of fat in the body and brings with physical and mental problems (1). According to the reports of World Health Organization (WHO) in 2016, the number of overweight or obese children under the age of five years is more than 41 millions, and the number of children between the ages of five and 19 years is more than 340 millions
(2). According to the results of the United States National Nutrition and Health Survey in 2015-2016, the prevalence of obesity was reported to be $42.8 \%$ in middle-aged adults, $13.9 \%$ in children aged $2-5$ years, $18.4 \%$ in children aged $6-11$ years and $20.6 \%$ in adolescents aged between 12 and 19 years (3). The prevalence of obesity, which is described as a disease of our age, is increasing day by day in children and adolescents in our country as well as in the world. While the obesity rate was $15.2 \%$ in children over 15 years of age in 2008 in Turkey, it rose to $19.9 \%$ in 2014 (4). The Project Research of Monitoring 
School-Age Children's Growth in Turkey (TOÇBi) conducted in 2009 revealed that the overweight rate was $14.3 \%$ and obesity rate was $6.5 \%$ in the children between six and nine years of age (5).

The prevalence of obesity in boys and girls aged 6-9 years in Europe has been found to range between $5 \%$ and $43 \%$ according to the WHO's study of the European Childhood Obesity Surveillance Initiative (COSI) (1). The results of COSITurkey 2013 (TUR) revealed that the percentage of lightweight was $14.2 \%$ and the rate of obesity was $8.3 \%$ in the children aged $7-8$ years and that $23.3 \%$ of boys and $21.6 \%$ of girls were overweight and obese (6). According to COSI-TUR 2016 data, overweight and obesity rates were determined to be $14.6 \%$ and $9.9 \%$, respectively, in the second-grade children (7).

Childhood obesity is frequently carried to later ages and forms the basis for many diseases (8). An obese child is highly likely to become overweight or obese in adulthood (9). In other words, overweight and obesity seen in childhood continue in adulthood and constitute the basis for many diseases such as cardiovascular diseases, hypertension, diabetes and respiratory problems (10). It, at the same time, causes a decrease in life expectancy at birth and adversely affects the quality of life. Lipid metabolism disorders, steatohepatitis, and type-2 diabetes, which are known to be associated with obesity, have recently become common in children and adolescents (8). In addition to these diseases, failures in education, skeletal system problems, cardiovascular diseases, and mental problems including lack of self-worth are also important problems faced by an obese child (11).

Such factors as family's obesity, socioeconomic status, education level, and family type play a role in the increase of childhood obesity prevalence. Besides, it is also noted that there is a strong relationship between obesity and the duration of a child's breastfeeding, nutritional characteristics, physical activity and television/computer use (12). Thus, the underlying factors need to be evaluated to understand the primary prevention of obesity. Although childhood obesity is an important and rapidly increasing public health problem, the measures implemented to prevent it remain inadequate today (13).

Considering all these conditions makes it important to define the incidence and risk factors of obesity among schoolage children, to plan and implement the attempts to increase healthy nutrition and physical activity. Accordingly, this study aims to determine the factors related to overweight and obesity in primary and secondary school children in Mersin.

\section{Methods}

This cross-sectional study was carried out in the children aged between five and 14 years in primary and secondary schools in Mersin, following the school health activities done by Mersin Public Health Directorate. The ethics committee approval was obtained from Non-Interventional Clinical Research Ethics Committee of Hacettepe University with the number 169695571126 dated July 26, 2017. The studies were carried out within the framework of the school health services cooperation protocol signed in May 2016 between the Ministry of Health and the Ministry of National Education of Turkey.

Before the research, the work conducted by Mersin Public Health Directorate was as follows; following the receipt of the institutional approval from the Public Health Agency of Turkey for the field study as a part of the school health studies, the parents and students were informed about the study and their consent forms were obtained. After this formal procedure, the height and weight of 205.605 children out of 247.156 children (except those who were absent and migrated to another city, and younger than 66 months and older than 14 years) studying at primary (including kindergarten) and secondary schools in the city center and districts of Mersin in 20172018 academic year were measured. Their body mass index (BMI) values were calculated and classified according to the criteria (Z-score) accepted by the WHO (14). As a result of this classification, it was found out that the prevalence of overweight or obesity was $34.5 \%$ among children aged 66 months and over in primary (including kindergarten) and secondary schools in Mersin. The same brand and model equipment with good calibration and accurate and reliable measurement was used in the anthropometric measurements. At the time of the measurement, each student's shoes, jacket, or other heavy clothing were removed and his/her pockets were emptied.

After the study conducted by Mersin Public Health Directorate, to determine the factors related to overweight and obesity, the sample size was calculated as 347 out of 205.605 people with an error rate of $5 \%$, confidence interval of $95 \%$ and overweight or obesity frequency of $34.5 \%$ in the Epi Info

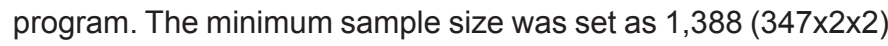
to represent gender (male-female) and education levels (primary and secondary). Taking the non-response rate $(25 \%)$ into consideration, the minimum sample size was calculated as 1,735 , and questionnaires were sent to 2,000 people considering the variables of the class and school location.

During the sampling process, the students' lists were sorted according to their BMIs, classes, genders, and a number from 1 to 102 was selected. Starting from this number, every $102^{\text {nd }}$ person was taken as sample.

The independent variables of the study were sociodemographic characteristics, feeding habits, time allocated for physical and other activities, children's BMI categories according to the parents' declarations and parents' BMI categories according to their declarations. And the dependent variable was the children's BMI values calculated by our measurements. 
The height and weight values of the parents were evaluated according to their declarations and categorized as weak $(<18.5)$, normal (18.5-24.9), overweight (25.0-29.9), and obese $(>30.0)$ in reference to the BMI values obtained (15).

Following the approval of the ethics committee, a questionnaire and informed consent form were sent to the children's parents.

\section{Statistical Analysis}

The data obtained from 1.980 students who accepted to participate in the study and answered the questionnaire were analyzed with the Statistical Package for the Social Sciences-25 package program. While descriptive variables were expressed as mean, standard deviation, number, and percentage, chi-square analysis was performed to compare categorical variables. The statistical significance in this study was considered to be $p<0.05$.

\section{Results}

The mean age of the 1.980 children included in the study was 9.28 \pm 2.53 (minimum-maximum: 5-14) years. After the BMI values were classified, it was found that $14.6 \%(n=289)$ of the students were obese, $21.5 \%(n=426)$ were overweight, $62.3 \%$ $(n=1233)$ were normal weight, $1.4 \%(n=27)$ were weak, and $0.3 \%(n=5)$ were very weak.

Males constituted $50.9 \%(n=1.007)$ of the current study group and $57.5 \%(n=1.139)$ of the participants were living in the central district. Those studying at secondary school formed $50.8 \%(n=1.006)$ of the whole group. While $38.3 \%(n=386)$ of boys were in the overweight or obese category, it was $33.8 \%$ $(n=329)$ for girls. Whereas there was no significant difference among the BMI categories according to gender $(p=0.108)$, it was found that the frequency of overweight or obesity was significantly higher in the age group of 13-14 years compared to the other groups $(p<0.001)$. Similarly, the prevalence of overweight or obesity was significantly higher in secondary school students than in primary school students $(p=0.002)$ (Table 1).

Of the residents in the central district, $62.9 \%(n=717)$ were of normal weight, $35.5 \%(n=404)$ were overweight or obese, and $1.6 \%(n=18)$ were weak or very weak while $61.4 \%(n=516)$ of those living in the periphery were normal weight, $37.0 \%$ $(n=311)$ were overweight or obese, and $1.7 \%(n=14)$ were weak or very weak. As a result, there was no statistically meaningful difference among BMI categories according to residence type $\left(x^{2}=0.524, p=0.769\right)$.

The children walking or cycling to or from school constituted $55.3 \%$ ( $n=1.094)$ of the group, but those commuting by a motor vehicle were $36.6 \%(n=724)$. According to the evaluation of the access type to school, there was no statistically significant difference among the BMI categories of those walking or cycling, using a motor vehicle and both $\left(x^{2}=2.840, p=0.585\right)$.

It was noted that $27.7 \% \quad(n=548)$ of the group did not devote any time to weekly sports and physical activity including weekends. As for the time spent in front of TV and computers, $18.6 \%(n=369)$ and $42.3 \% \quad(n=837)$ spent more than two hours on TV and computers on weekdays and on weekends, respectively. The frequency of overweight or obesity $(30.7 \%)$ was significantly lower in those devoting more than 4 hours to sports and physical activities including the weekend when compared to the other groups $\left(x^{2}=20,346, p<0.001\right)$. It was also found that the frequency of overweight or obesity decreased as the time spent on TV-computers per day during the week or at the weekend decreased (Table 2).

BMI categories were found to differ according to the frequency of having breakfast weekly. While $95.7 \%(n=22)$ of those who had breakfast every day of the week were in the normal weight category, the frequency of normal weight was $51.1 \%(n=46)$ and the frequency of overweight or obesity was $45.6 \%(n=41)$ in those never having breakfast $\left(x^{2}=44.313\right.$, $\mathrm{p}<0.001)$.

\begin{tabular}{|c|c|c|c|c|c|c|c|c|c|}
\hline & & \multicolumn{2}{|c|}{$\begin{array}{l}\text { Weak and very } \\
\text { weak }\end{array}$} & \multicolumn{2}{|c|}{ Normal weight } & \multicolumn{2}{|c|}{$\begin{array}{l}\text { Overweight or } \\
\text { obese }\end{array}$} & $x^{2}$ & p \\
\hline \multirow{2}{*}{ Gender } & Male $(50.9 \%)$ & 15 & 1.5 & 606 & 60.2 & 386 & 38.3 & \multirow{2}{*}{4,444} & \multirow{2}{*}{0.108} \\
\hline & Female $(49.1 \%)$ & 17 & 1.7 & 627 & 64.4 & 329 & 33.8 & & \\
\hline \multirow[t]{3}{*}{ Age group } & $9-10$ years $(21.8 \%)$ & 12 & 2.8 & 267 & 61.8 & 153 & 35.4 & \multirow[t]{3}{*}{34,872} & \multirow[t]{3}{*}{$<0.001$} \\
\hline & $11-12$ years $(23.3 \%)$ & 8 & 1.7 & 290 & 62.9 & 163 & 35.4 & & \\
\hline & $13-14$ years $(13.4 \%)$ & 5 & 1.9 & 131 & 49.4 & 129 & 48.7 & & \\
\hline School category & Primary school (49.2\%) & 10 & 1.0 & 641 & 65.8 & 323 & 33.2 & 12,592 & 0.002 \\
\hline
\end{tabular}


The group's BMI categories varied according to vegetable, whole milk, and yogurt-tzatziki-ayran consumption, as well. While $32.3 \%(n=113)$ of those consuming vegetables every day of the week were found to be overweight or obese, it was $34.8 \%(n=200)$ in those who consumed vegetables frequently (4-6 days a week), $39.1 \%(n=313)$ in those rarely (1-3 days) consuming, $35.6 \%(n=58)$ in those consuming less than one a week, and $33.7 \%(n=31)$ in those who never consumed. This difference in the groups was statistically significant $\left(x^{2}=20.438, p=0.009\right)$. As for the consumption of whole milk, the frequency of overweight or obesity was $30.5 \%(n=99)$ in the students who consumed it every day of the week, $36.2 \%$ $(n=123)$ in those consuming frequently (4-9 days), 32.5 $(n=160)$ in those consuming rarely (1-3 days), and $41.6 \%$ $(n=107)$ in those consuming less than once a week. And it was found that $40.0 \%(n=226)$ of the students who did not consume whole milk were in the overweight or obese category $\left(x^{2}=17.332, p=0.027\right)$. While the prevalence of overweight or obesity was $32.2 \%(n=19)$ in those who did not consume any yogurt, tzatziki, and ayran, it was $34.3 \%(n=23)$ in those who consumed less than once a week, $36.7 \%(n=130)$ in those rarely (1-3 days) consuming, $40.5 \%(n=265)$ in those who consumed frequently (4-6 days), and $32.9 \%(n=278)$ in those who consumed every day $\left(x^{2}=17.544, p=0.025\right)$.

The BMI categories of the participants were not found to be statistically different according to their consumption of fresh fruit, ready-made $100 \%$ fruit juice, freshly squeezed fruit juice, carbonated drinks (cola etc.), dietary drinks other than milk, low or semi-skimmed milk, cheese, pudding and other instant dairy products, salty snacks such as meat, fish, chips, sugar bar, chocolate dessert, biscuits, cakes, pastry, cookies, pizza, pita, lahmacun and French fries ( $p>0.05)$.

There was no statistically significant difference among $\mathrm{BMI}$ categories according to the total number of children in the family, either $\left(x^{2}=10.825, p=0.212\right)$. According to the answers of the families about how they regarded their children's weight, the BMI categories were statistically significantly different. The children of $93.2 \%(n=221)$ of those who thought their child were overweight, the children of $92.6 \%(n=25)$ were obese, the children of $34.7 \% \quad(n=450)$ of those who thought their child were normal weight, the children of $2.8 \%(n=11)$ were underweight and $25.8 \%(n=8)$ of those who did not express any opinion were overweight or obese $\left(x^{2}=611.534\right.$, p <0.001) (Table 3).

Children's BMI categories were significantly different according to maternal education level, job, and BMI category. The highest prevalence of overweight or obesity was found in the children of college/university graduate mothers with $43.9 \% \quad(n=115) \quad\left(x^{2}=27.311, p<0.001\right)$. According to the evaluation of the mother's employment (job) status, the prevalence of being overweight or obese was $80.0 \%$ $(n=4)$ in the children whose mothers were retired, and $34.6 \%(n=546)$ in those whose mothers were housewives/ unemployed $\left(x^{2}=16.934, p=0.031\right)$. When the BMl categories of the children were compared according to the mother's BMI category, $46.8 \%(n=177)$ of the children whose mothers were obese were overweight or obese, and this value was found to be significantly higher than the non-obese mothers $\left(x^{2}=44.748, p<0.001\right)$ (Table 3).

BMI categories of the children did not show a significant difference regarding fathers' job status while they differed according to fathers' educational levels and BMI categories. The incidence of overweight or obesity was found to be $42.2 \%$ $(n=19)$ in the children whose fathers were illiterate $\left(x^{2}=15.599\right.$, $p=0.048)$. And $49.2 \%(n=203)$ of the children whose fathers were obese were found to be overweight or obese $\left(x^{2}=63.152\right.$, p<0.001) (Table 3).

Table 2. Distribution of body mass index categories according to the time set aside for the TV-computer and physical activity by the students $(n=1.980)$

\begin{tabular}{|c|c|c|c|c|c|c|c|c|c|}
\hline & & \multicolumn{2}{|c|}{$\begin{array}{l}\text { Weak and very } \\
\text { weak }\end{array}$} & \multicolumn{2}{|c|}{ Normal weight } & \multicolumn{2}{|c|}{$\begin{array}{l}\text { Overweight or } \\
\text { obese }\end{array}$} & \multirow[t]{2}{*}{$\chi^{2}$} & \multirow[t]{2}{*}{$\mathbf{p}$} \\
\hline & & $\mathrm{n}$ & $\%$ & $\mathrm{n}$ & $\%$ & $\mathbf{n}$ & $\%$ & & \\
\hline \multirow{3}{*}{$\begin{array}{l}\text { Allocated time for sports- } \\
\text { physical activity, including } \\
\text { weekend (per week) }\end{array}$} & $0(27.7 \%)$ & 16 & 2.9 & 322 & 68.8 & 210 & 38.3 & \multirow{3}{*}{20,346} & \multirow{3}{*}{$<0.001$} \\
\hline & $1-4$ hours (42.6\%) & 11 & 1.3 & 508 & 60.3 & 324 & 38.4 & & \\
\hline & $>4$ hours $(29.7 \%)$ & 5 & 0.8 & 403 & 68.4 & 181 & 30.7 & & \\
\hline \multirow{3}{*}{$\begin{array}{l}\text { Time spent on TV-computer on } \\
\text { weekdays (per day) }\end{array}$} & $0(23.4 \%)$ & 10 & 2.2 & 307 & 66.3 & 146 & 31.3 & \multirow{3}{*}{9,717} & \multirow{3}{*}{0.045} \\
\hline & $1-2$ hours $(58.0 \%)$ & 18 & 1.6 & 714 & 62.2 & 416 & 36.2 & & \\
\hline & $>2$ hours $(18.6 \%)$ & 4 & 1.1 & 212 & 57.5 & 153 & 41.5 & & \\
\hline \multirow{3}{*}{$\begin{array}{l}\text { Time spent on TV-computer at } \\
\text { the weekend (per day) }\end{array}$} & $0(16.7 \%)$ & 11 & 3.3 & 213 & 64.4 & 107 & 32.3 & \multirow{3}{*}{14,941} & \multirow{3}{*}{0.005} \\
\hline & $1-2$ hours $(41.0 \%)$ & 15 & 1.8 & 515 & 63.4 & 282 & 34.7 & & \\
\hline & $>2$ hours $(42.3 \%)$ & 6 & 0.7 & 505 & 60.3 & 326 & 38.9 & & \\
\hline
\end{tabular}




\begin{tabular}{|c|c|c|c|c|c|c|c|c|c|}
\hline & & \multicolumn{2}{|c|}{$\begin{array}{l}\text { Weak or very } \\
\text { weak }\end{array}$} & \multicolumn{2}{|c|}{ Normal } & \multicolumn{2}{|c|}{$\begin{array}{l}\text { Overweight } \\
\text { or obese }\end{array}$} & \multirow[t]{2}{*}{$x^{2}$} & \multirow[t]{2}{*}{$\mathbf{p}$} \\
\hline & & $\mathbf{n}$ & $\%$ & $\mathbf{n}$ & $\%$ & $\mathbf{n}$ & $\%$ & & \\
\hline \multirow{5}{*}{$\begin{array}{l}\text { Total number of } \\
\text { children }\end{array}$} & $1(9.2 \%)$ & 3 & 1.6 & 102 & 56.0 & 77 & 42.3 & \multirow{5}{*}{10,825} & \multirow{5}{*}{0.212} \\
\hline & $2(38.6 \%)$ & 10 & 1.3 & 479 & 62.7 & 275 & 36.0 & & \\
\hline & $3(30.6)$ & 7 & 1.2 & 390 & 64.5 & 208 & 34.4 & & \\
\hline & $4(10.8 \%)$ & 5 & 2.3 & 126 & 58.9 & 83 & 38.8 & & \\
\hline & 5 and over $(10.9 \%)$ & 7 & 3.3 & 136 & 63.3 & 72 & 33.5 & & \\
\hline \multirow{5}{*}{$\begin{array}{l}\text { Do you think your } \\
\text { child's weight? }\end{array}$} & Underweight (19.6\%) & 25 & 6.4 & 352 & 90.7 & 11 & 2.8 & \multirow{5}{*}{611,534} & \multirow{5}{*}{$<0.001$} \\
\hline & Normal weight $(65.5 \%)$ & 7 & 0.5 & 840 & 64.8 & 450 & 34.7 & & \\
\hline & Overweight (12.0\%) & 0 & 0.0 & 16 & 6.8 & 221 & 93.2 & & \\
\hline & Fat $(1.4 \%)$ & 0 & 0.0 & 2 & 7.4 & 25 & 92.6 & & \\
\hline & Don't know/not specified (1.6\%) & 0 & 0.0 & 23 & 74.2 & 8 & 25.8 & & \\
\hline \multirow{5}{*}{$\begin{array}{l}\text { Mother's education } \\
(\mathrm{n}=1.954)^{\star}\end{array}$} & Not vote $(11.0 \%)$ & 6 & 2.8 & 130 & 60.5 & 79 & 36.7 & \multirow{5}{*}{27,311} & \multirow{5}{*}{0.001} \\
\hline & Literate $(5.4 \%)$ & 5 & 4.8 & 58 & 55.2 & 42 & 40.0 & & \\
\hline & Primary school (43.4\%) & 13 & 1.5 & 523 & 61.6 & 313 & 36.9 & & \\
\hline & Secondary/high school (26.8\%) & 4 & 0.8 & 360 & 68.8 & 159 & 30.4 & & \\
\hline & College/university $(13.4 \%)$ & 4 & 1.5 & 143 & 54.6 & 115 & 43.9 & & \\
\hline \multirow{5}{*}{$\begin{array}{l}\text { Mother's job } \\
(\mathrm{n}=1.954)^{*}\end{array}$} & Housewife/unemployed (80.9\%) & 26 & 1.6 & 1.008 & 63.8 & 546 & 34.6 & \multirow{5}{*}{16,934} & \multirow{5}{*}{0.031} \\
\hline & Worker $(7.3 \%)$ & 4 & 2.8 & 76 & 53.1 & 63 & 44.1 & & \\
\hline & Officer $(6.4 \%)$ & 0 & 0.0 & 71 & 56.3 & 55 & 43.7 & & \\
\hline & Self-employed (5.1\%) & 2 & 2.0 & 58 & 58.0 & 40 & 40.0 & & \\
\hline & Retired $(0.3 \%)$ & 0 & 0.0 & 1 & 20.0 & 4 & 80.0 & & \\
\hline \multirow{4}{*}{$\begin{array}{l}\text { Mother's BMI } \\
\text { category }(n=1.954)^{*}\end{array}$} & Very poor or poor (1.5\%) & 1 & 3.3 & 23 & 76.7 & 6 & 20.0 & \multirow{4}{*}{44,748} & \multirow{4}{*}{$<0.001$} \\
\hline & Normal $(39.9 \%)$ & 17 & 2.2 & 537 & 68.8 & 226 & 29.0 & & \\
\hline & Overweight (39.2\%) & 12 & 1.6 & 455 & 59.4 & 299 & 39.0 & & \\
\hline & Obese $(19.3 \%)$ & 2 & 0.5 & 199 & 52.6 & 177 & 46.8 & & \\
\hline \multirow{5}{*}{$\begin{array}{l}\text { Father's education } \\
(\mathrm{n}=1.938)^{\star *}\end{array}$} & Not voted $(2.3 \%)$ & 1 & 2.2 & 25 & 55.6 & 19 & 42.2 & \multirow{5}{*}{15,599} & \\
\hline & Literate $(4.2 \%)$ & 4 & 4.9 & 46 & 56.8 & 31 & 38.3 & & \\
\hline & Primary school (41.4\%) & 18 & 2.2 & 505 & 63.0 & 279 & 34.8 & & 0.048 \\
\hline & Secondary/high school (34.3\%) & 4 & 0.6 & 430 & 64.7 & 231 & 34.7 & & \\
\hline & College/university (17.8\%) & 5 & 1.4 & 205 & 59.4 & 135 & 39.1 & & \\
\hline Your father's job & Unemployed $(6.0 \%)$ & 5 & 4.3 & 61 & 52.6 & 50 & 43.1 & & \\
\hline$(n=1.938)^{\star *}$ & Worker $(42.8 \%)$ & 14 & 1.7 & 538 & 64.9 & 277 & 33.4 & & \\
\hline & Officer $(9.6 \%)$ & 2 & 1.1 & 117 & 62.9 & 67 & 36.0 & 12,288 & 0.139 \\
\hline & Self-employment (38.6\%) & 10 & 1.3 & 461 & 61.5 & 278 & 37.1 & & \\
\hline & Retired (3.0\%) & 1 & 1.7 & 34 & 58.6 & 23 & 39.7 & & \\
\hline Father's BMI category & Very poor or poor $(0.5 \%)$ & 0 & 0.0 & 8 & 88.9 & 1 & 11.1 & & \\
\hline$(n=1.938)^{\star *}$ & Normal $(28.2 \%)$ & 13 & 2.4 & 396 & 72.5 & 137 & 25.1 & 63152 & $<0001$ \\
\hline & Overweight (50.1\%) & 15 & 1.5 & 601 & 62.0 & 354 & 36.5 & 03,152 & \\
\hline & Obese $(21.3 \%)$ & 4 & 1.0 & 206 & 49.9 & 203 & 49.2 & & \\
\hline $\begin{array}{l}\text { Monthly household } \\
\text { income }\end{array}$ & $\begin{array}{l}\text { Minimum wage (1.404) and below } \\
(53.4 \%)\end{array}$ & 21 & 2.0 & 659 & 62.3 & 377 & 35.7 & & \\
\hline & $1.405-3.000(29.4 \%)$ & 7 & 1.2 & 362 & 62.2 & 213 & 36.6 & 5,885 & 0.436 \\
\hline & $3.001-5.000(10.7 \%)$ & 3 & 1.4 & 139 & 65.9 & 69 & 32.7 & & \\
\hline & 5.001 and above $(6.6 \%)$ & 1 & 0.8 & 73 & 56.2 & 56 & 43.1 & & \\
\hline
\end{tabular}




\begin{tabular}{|c|c|c|c|c|c|c|c|c|c|}
\hline & & \multicolumn{2}{|c|}{$\begin{array}{l}\text { Weak or very } \\
\text { weak }\end{array}$} & \multicolumn{2}{|c|}{ Normal } & \multicolumn{2}{|c|}{$\begin{array}{l}\text { Overweight } \\
\text { or obese }\end{array}$} & $\chi^{2}$ & $\mathbf{p}$ \\
\hline \multirow{3}{*}{$\begin{array}{l}\text { Financial situation } \\
\text { assessment }\end{array}$} & One month passes easily ( $22.4 \%)$ & 6 & 1.4 & 273 & 61.6 & 164 & 37.0 & \multirow{3}{*}{6,369} & \multirow{3}{*}{0.383} \\
\hline & $\begin{array}{l}\text { One month passes without much } \\
\text { difficulty }(27.7 \%)\end{array}$ & 5 & 0.9 & 356 & 65.0 & 187 & 34.1 & & \\
\hline & $\begin{array}{l}\text { Cannot make the end of the month } \\
(16.9 \%)\end{array}$ & 8 & 2.4 & 197 & 58.8 & 130 & 38.8 & & \\
\hline $\begin{array}{l}\text { The percentages in pare } \\
{ }^{*} \text { Twenty-six children with } \\
{ }^{* *} \text { Forty-two children with } \\
\text { BMI: Body mass index }\end{array}$ & $\begin{array}{l}\text { indicate the distribution of the related param } \\
\text { ormation about their mothers were excluded fr } \\
\text { prmation about their fathers were excluded fror }\end{array}$ & $\begin{array}{l}\text { ter witl } \\
m \text { the } \\
\text { the el }\end{array}$ & $\begin{array}{l}\text { the group. } \\
\text { aluation. } \\
\text { dation. }\end{array}$ & & & & & & \\
\hline
\end{tabular}

According to monthly household income and financial status assessment, there was no significant difference among the children's BMI categories ( $p>0.05$ ) (Table 3).

\section{Discussion}

Childhood obesity affects an individual's whole life. Also, it is an important health problem in terms of causing many chronic diseases. The rapid increase in obesity requires urgent measures, firstly, to stop and then reduce the upward trend. While there were 32 million overweight and obese children in the $0-5$ age group in the world in 1990, it increased up to 41 millions in 2016. During this period, the number of overweight or obese children in the age group of 0-5 years in Africa increased from four millions to nine millions. The rate of increase in overweight and obesity in developing countries is more than $30 \%$, and a significant majority of overweight and obese children live in these countries $(11,15)$. The prevalence of overweight and obesity among children and adolescents (5-19 years) has dramatically increased from $4 \%$ to $18 \%$ between the years 1975 and 2016 . The increase is similar among both boys and girls. In 2016, $18 \%$ of girls and $19 \%$ of boys were overweight. While the prevalence of obesity in children and adolescents was less than $1 \%$ in 1975 , it increased to approximately 7\% in 2016 (16).

In the present study, the prevalence of overweight was found to be $21.5 \%$ and obesity was $14.6 \%$ in children aged $5-14$ years. When compared to our study, the prevalence of obesity was high in the studies performed by different researchers in the same age group in Ankara, Erzurum, and Konya (17-19). However, in the studies conducted in Izmir and Ankara, it was found to be lower $(20,21)$. The different results among the studies may be due to differences in the effects of socioeconomic, climatic and cultural characteristics of the study areas on nutritional status and physical activity, as well as differences in sample size and diagnostic methods used.

In our study, the prevalence of overweight or obesity was highest in the age group of $13-14$ years with $48.7 \%$. Similarly, it was higher in the older age group in middle school students than in primary school students. In a study conducted in the age group of 6-15 years in Mugla, the prevalence of obesity was found to be significantly higher in children aged 10 years compared to children in other age groups (22). However, in another study conducted on primary school students in Izmir, the age group with the highest frequency of obesity was determined to be 12 years of age (23). This may be associated with the relationship between obesity and puberty. The increase in the tendency to spend more time outside the home and consuming fast food for socialization in this age group may be among the reasons as well.

Although there was a higher incidence of overweight or obesity in men in our study, this difference was not statistically significant. In a study conducted in Izmir, obesity was found to be more common in all age groups of men (20). Likewise, the frequency of obesity was found to be significantly higher in boys than in girls in a research conducted in Duzce (24).

In our study, no significant difference was found among BMI values regarding the type of school access. The ways of going to school in primary school students at two different socioeconomic levels were examined in a study conducted in Istanbul. A significant difference was found among BMI values with regard to the types of access to school (25).

One of the most important factors affecting obesity is the lack of desired physical activity. Urban and apartment life, narrow playgrounds in the streets as a result of modern life and the increase in the time spent on TV and computers due to technological developments decrease the physical activity and create a still lifestyle in children $(26,27)$.

Preschoolers and school-age children should be approached differently in terms of performing physical activity. Preschoolers need to play games for two hours a day in a physically active way while one hour of physical activity to perspire is enough for school-age children (28). In our study group, the incidence of obesity was less in those who had more than four hours per week for physical activity including weekends. Nonetheless, no significant difference was found among BMI categories 
according to the method of school access (walking or cycling, motor vehicle). The prevalence of obesity was found to be high among the students who did not play games requiring movement $(14.3 \%)$ and those who did not perform regular sports $(9.7 \%)$ in a study conducted in Erzincan (29). In a study conducted in Elazig, the frequency of obesity was found to be higher in those who went to school by a vehicle than those who went on foot, but the difference was not significant (30). As a result, children should be encouraged to do more physical activities by explaining the importance of it by their families and teachers, and safe sports areas should be established in schools and other living spaces as far as physical settings are concerned.

In our study group, it was found that the frequency of overweight or obesity increased as the time spent on computers and TV increased. With the development of technology, the time spent on devices such as computers, television, and mobile phones increases. The rise in the duration of the TV watching in children increases the frequency of obesity, as well. It is known that children need to be physically active and to have adequate sleep. They are not recommended to watch TV for more than two hours $(31,32)$. In a study conducted in Corum, a positive correlation was found between the students' BMI categories and the time spent in front of computers and television, which is also in harmony with the present study. As the time spent in front of computers and television increases, so do BMI values (33). In a study conducted in Elazig, obesity was found to be more frequent in those who spent four hours or more in front of the television than those who spent 1-3 hours (30).

In the current study, no significant difference was found among the BMI categories according to socioeconomic levels. However, in the study conducted by Pirinççi et al. (34) in the province of Elazig, an increase in obesity was found in parallel with the income level. Still in another study conducted in Elazig, it was found that there was no difference in the prevalence of obesity according to income levels (30). This difference is thought to be due to the fact that the data on the economic situation are based on the verbal declaration of the families.

When the frequency of having breakfast, which is one of the important dietary habits, and BMI values were evaluated in our study, the frequency of being overweight or obese was found to be statistically lower in those who had daily breakfast. The prevalence of obesity was reported to be higher in those who did not eat regularly and did not have breakfast on a regular basis in the provinces of Ankara, which is also consistent with our study findings (21). Moreover, in a study conducted in Erzurum, the frequency of obesity was found to be significantly higher in children who did not eat breakfast, which is compatible with our study as well (18). It is known that skipping the breakfast leads to susceptibility to obesity. This is attributed to the fact that the feeling of hunger is more dominant during the day in those who do not have breakfast, thereby necessitating eating more or resulting in a diet with higher energy content (35). Therefore, families, teachers, and children should be informed about the importance of the habit of having breakfast every day. Nutritional hours suitable for breakfast should be established until the end of primary education at schools, and children should be encouraged to have breakfast during these hours.

Even if the frequency of overweight or obesity in our study was lower in those who consumed fresh fruit every day, it was not statistically significant. In a study conducted in Erzincan, however, the prevalence of obesity among those consuming fruits and vegetables during snacks was $2.9 \%$, which seems to be lower than in other groups (29). Another study conducted in Greece in 2012 revealed that the prevalence of obesity was $7.3 \%$ and the frequency of overweight was $23.9 \%$ with a significant relationship found between skipping breakfast, not consuming fruit and vegetables and the prevalence of obesity (36).

Not only was the frequency of obesity in the students who consumed whole milk, yogurt, tzatziki and ayran every day found to be lower in the present study but also the overweight or obesity prevalence was determined to be lower in them. Similarly, a study conducted abroad showed that the risk of low obesity was associated with the consumption of whole milk (37). As a result, whole milk consumption in children is reported to be associated with low BMI values (38).

In this study, there was no significant difference among BMI categories regarding the consumption of fizzy drinks (cola, etc.), salty snacks such as chips, candy bars, and chocolate dessert. But in a study conducted in Ankara, it was found that the prevalence of obesity was higher in students who consumed sugary fizzy drinks more (21).

The frequency of obesity was found to be high in children with high family income levels in this research, but it was not statistically significant. The obesity rate was found to be significantly higher in children with high family income levels according to a study conducted in Erzurum (18).

In our study, the frequency of obesity was found to be significantly higher in mothers with high school and university education. And the highest prevalence of obesity was seen in the children of retired mothers. Although there was no significant difference among the BMI categories according to the father's job status, the frequency of overweight or obese was found to be significantly higher in the fathers who were illiterate and graduated from college/university. A study conducted in Ankara revealed that the frequency of obesity was higher in the children of highly educated mothers, although not statistically significant. No significant relationship was found between the mother's occupation and obesity in the same study (21). In a research conducted in Izmir, obesity was found to be related to the educational level of the parents (20). 
In our study, the incidence of being overweight or obese was higher in the children whose mother or father was in the obese category than other groups. In the Australian National Nutrition Survey, the relationship between 1.581 overweight or obese children aged 7-15 years and parental BMI was examined and the incidence of obesity was found to be higher in children with overweight or obese mothers (39). In a study conducted in Mugla, a positive and significant relationship was found between BMI values of mothers and children. Similarly, a significant positive correlation was found between BMI values of fathers and children, too (22). In a study comparing patients who visited the clinic for obesity but did not have any problems related to obesity, it was determined that the presence of an obese person in the family affected the incidence of obesity in the study group (40).

Since the weight and height of the parents are taken according to their own statements, data that do not reflect current or accurate information can be found.

\section{Conclusion}

The factors affecting childhood obesity identified in the studies conducted in Turkey have also become apparent in the current research we did on the school children aged 5-14 years in Mersin province. This study is expected to support further studies, to be conducted both regionally and nationally, for the early recognition of childhood obesity and the timely implementation of the necessary interventions.

\section{Ethics}

Ethics Committee Approval: The ethics committee approval was obtained from Non-Interventional Clinical Research Ethics Committee of Hacettepe University with the number 169695571126 dated July 26, 2017.

Informed Consent: Parents' approval was obtained.

Peer-review: Externally and internally peer-reviewed.

\section{Authorship Contributions}

Surgical and Medical Practices: S.D., S.Ü., Concept: S.D., H.Ş., S.Ü., Design: S.D., H.Ş., M.K., S.Ü., Data Collection or Processing: S.D., M.K., S.Ü., Z.K., Analysis or Interpretation: S.D., H.Ş., M.K., G.K., Literature Search: S.D., H.Ş., Z.K., G.K., Writing: S.D., H.Ş., Z.K., S.Ü.

Conflict of Interest: No conflict of interest was declared by the authors.

Financial Disclosure: The authors declared that this study received no financial support.

\section{References}

1. WHO European Childhood Obesity Surveillance Initiative (COSI). Last Accessed Date: 28.10.2019. Available from: http://www.euro.who.int/en/health-topics/disease- prevention/nutrition/activities/who-european-childhoodobesity-surveillance-initiative-cosi

2. Commission on Ending Childhood Obesity. Last Accessed Date: 28.10.2019. Available from: http://www.who.int/endchildhood-obesity/en/

3. National Health and Nutrition Examination Survey (2017). Prevalence of obesity among adults and youth: united states, 2015-2016. Nchs Data Brief No.288. Last Accessed Date: 19.11.2019. Available from: https://www.cdc.gov/ nchs/products/databriefs/db288.htm

4. Türkiye İstatistik Kurumu (2015). Last Accessed Date: 08.11.2019. Available from: http://www.tuik.gov.tr/ basinodasi/haberler/2015_58_20151008.pdf

5. Sağlık Bakanlığı. Turkey in the school age children (610 age group) monitoring growth project research report (TOÇBi). 1st ed. Ankara, Türkiye: Kuban Matbaacılık Yayıncılık; 2011.

6. Özcebe H, Bağcı AT, Keskinkılıç B, Yardım N, Çelikay N, Çelikcan E. Childhood Obesity Research (Cosi-Tr) Preliminary Report. Ankara 2013. Last Accessed Date: 18.11.2019. Available from: http://www.diabetcemiyeti.org/ var/cdn/a/f/cosi-tr-sonuclari.pdf

7. Turkey Childhood (Elementary 2nd Grade Students) Obesity Research Cosi-Tur 2016, Ankara 2017. Last Accessed Date: 09.11.2019. Available from: https:// hsgm.saglik.gov.tr/depo/haberler/turkiye-cocukluk-cagisismanlik/cosi-tur

8. Llewellyn A, Simmonds M, Owen CG, Woolacott N. Childhood obesity as a predictor of morbidity in adulthood: a systematic review and meta-analysis. Obes Rev. 2016;17:56-67.

9. Whitaker RC, Wright JA, Pepe MS, Seidel KD, Dietz WH. Predicting obesity in young adulthood from childhood and parental obesity. N Engl J Med. 1997;337:926-927.

10. Sağlık Bakanlığı. In Turkey in school age children (6-10 age group) monitoring growth of (TOÇBi) project research report. Sağlık Bakanlığı Temel Sağlık Hizmetleri Genel Müdürlüğü, Ankara 2011.

11. Childhood Obesity Surveillance in the Who European Region. Last Accessed Date: 29.10.2019. Available from: http:// www.euro.who.int/_data/assets/pdf_file/0020/123176/ factsheet_5.pdf

12. Bereket A, Atay Z. Current status of childhood obesity and its associated morbidities in Turkey. J Clin Res Pediatr Endocrinol. 2012;4:1-7.

13. Reilly JJ. Evidence-based obesity prevention in childhood and adolescence: critique of recent etiological studies, preventive interventions, and policies. Adv Nutr. 2012;3:636-641.

14. WHO. BMI-For-Age (5-19 Years). Last Accessed Date: 18.11.2019. Available from: http://www.who.int/growthref/ who2007_bmi_for_age/en/

15. WHO. Obesity and overweight. Last Accessed Date: 18.11.2019. Available from: http://www.who.int/ mediacentre/factsheets/fs311/en/ 
16. Overweight and obesity children and adolescents aged 5-19. Last Accessed Date: 19.11.2019. Available from: https://www.who.int/gho/ncd/risk_factors/overweight_ adolescents_text/en/

17. Savaşhan Ç, Sarı O, Aydoğan Ü, Erdal M. Obesity prevalence and risk factors in primary school-age children. Türk Aile Hek Derg. 2015;19:14-21.

18. Ay EG. The prevalence of obesity in school-age children in Erzurum city center and its relationship with eating habits. Masther Thesis. Erzurum Atatürk University 2014.

19. Yazar A, Kılıçaslan M, Akın F, Arslan Ş. Obesity prevalence in children between the ages of 6-18 in Konya. Bozok Tıp Derg. 2019;9:123-129.

20. Özilbey P, Ergör G. Determination of obesity prevalence and nutritional habits in primary school students in Güzelbahçe district of İzmir province. Turk J Public Health. 2015;13:30.

21. Çınar S. Examination of obesity in 7-14 age group at different socio-economic levels. Master Thesis. Ankara Hacettepe University 2013.

22. Süzek H, Arı Z, Uyanık BS. Prevalence of overweight and obesity among 6-15 year old school children living in Muğla. Türk Biyokimya Dergisi. 2005;30:290-295.

23. Yılmaz M, Kundakçı GA, Dereli F, Oztornacı BO, Cetişli NE. Obesity and related characteristics obesity and related factors by age and gender in primary school students. JCP. 2019;17:127-140.

24. Oruç D, Eker F. Prevalence of obesity in students in the schools in Akçakoca district of Düzce province. 15. Ulusal Halk Sağlığı Kongresi, 2012, 2-6 Ekim, Bursa, Türkiye.

25. Demir HP. Evaluation of nutrition, physical activity and determination of obesity prevalence in different socioeconomic primary school children. Doctoral Thesis. İstanbul University 2011.

26. Çifçili S, Ünalan P, Kalaça Ç, Apaydın Ç, Uzuner, A. Childhood, obesity, television. Türkiye Klinikleri J Pediatr. 2003;12:67-71.

27. Özkan A, Köklü Y, Kayıhan G, Alemdaroğlu U, Ersöz G. The role of physical activity and exercise in the prevention and treatment of obesity. Uluslararası Hakemli Akademik Spor Sağlık ve Tıp Bilimleri Dergisi. 2013;3:48-63.

28. Physical Activity Guidelines for School-Aged Children and Adolescents. Last Accessed Date: 10.10.2019. Available from: https://www.cdc.gov/healthyschools/physicalactivity/ guidelines.htm
29. Karahan FF. Prevalence of obesity and effective factors in secondary school students studying in Erzincan city center. Master's Thesis. Erzurum Atatürk University 2015.

30. Aksakal BY, Oğuzöncül AF. Studying in secondary education in Elazig city center examination of obesity prevalence in students and affecting factors. Dicle Tip Dergisi. 2017;44:13-23.

31. Reilly JJ, Armstrong J, Dorosty AR, et al. Early life risk factors for obesity in childhood: cohort study. BMJ 2005;330:1357.

32. Sugimori H, Yoshida K, Izuno T, et al. Analysis of factors that influence body mass index from ages 3 to 6 years: A study based on the toyama cohort study. Pediatr Int. 2004;46:302-310.

33. Bekar N. Prevalence of obesity in 7-14 age group children in a primary school. Master's thesis. Ankara Gazi University 2010.

34. Pirinççi E, Durmuş B, Açık A, Gündoğdu C. Prevalence of overweight and obesity in Elazig central primary education students. XII. Ulusal Halk Sağlığı Kongresi, Ankara, Kongre Kitabı 21-25 Ekim 2008:ss.378.

35. Smetanina N, Albaviciute E, Babinska V, et al. Prevalence of overweight/obesity in relation to dietary habits and lifestyle among 7-17 years old children and adolescents in Lithuania. BMC Public Health. 2015;15:1001.

36. Jelastopulu E, Kallinezos P, Merekoulias G, Alexopoulos EC, Sapountzi-Krepia D. Prevalance and risk factors of excessweight in school children in west Greece. Nurs Health Sci. 2012;14:372-380.

37. Beck AL, Heyman M, Chao C, Wojcicki J. Full fat milk consumption protects against severe childhood obesity in latinos. Prev Med Rep 2017;8:1-5.

38. Vanderhout SM, Birken CS, Parkin PC, Lebovic G, Chen Y, O'connor DL. Relation between milk-fat percentage, vitamin D, and BMI Zscore in early childhood. Am J Clin Nutr. 2016;104:1657-1664.

39. Wang Z, Patterson CM, Hills AP. Association between overweight or obesity and household income and parental body mass index in Australian youth: analysis of the Australian national nutrition survey, 1995. Asia Pac J Clin Nutr. 2002;11:200-205.

40. Ulutaş AP, Atla P, Say ZA, Sarı E. Investigation of the factors affecting the formation of 6-18 years school-age children obesity. Zeynep Kamil Tıp Bülteni. 2014;45:192196. 